palliation and not a cure. No artificial valve can yet support the 40 million heart beats a year as efficiently as a healthy natural one.

1 Harken, D E, et al, fournal of Thoracic and Cardiovascular Surgery, 1960, 40, 744.

2 Starr, A, and Edwards, M L, Annals of Surgery, 1961, 154, 726.

3 Tofler, O B, British Heart fournal, 1970, 32, 771.

4 Hylen, J C, American Heart fournal, 1971, 81, 299.

5 McGoon, D C, British Heart fournal, 1971, 33, suppl, p 35.

${ }^{6}$ Ross, D N, Circulation, 1972, 45, 1259.

${ }^{7}$ McGoon, D C, Mayo Clinic Proceedings, 1974, 49, 233.

${ }^{8}$ Angell, W W, de Lanerolle, P, and Shumway, N E, Progress in Cardiovascular Diseases, 1973, 15, 589.

' Starr, A, et al, Annals of Thoracic Surgery, 1975, 19, 289.

10 Barclay, R S, et al, British Heart fournal, 1972, 34, 129.

11 Cleland, J, and Molloy, P F, Thorax, 1973, 28, 41.

12 Larsen, G L, Alexander, J A, and Stanford, W, Annals of Thoracic Surgery, 1977, 23, 323.

${ }^{13}$ Limet, R, Lepage, G, and Grondin, C M, Annals of Thoracic Surgery, $1977,23,529$.

14 Sullivan, J M, Harker, D E, and Gorlin, R, New England fournal of Medicine, 1971, 284, 1391.

15 Dale, J, et al, American Heart fournal, 1977, 94, 101

${ }_{16}$ Crexells, C, et al, American Heart fournal, 1972, 84, 161

17 Slater, S D, et al, Thorax, 1974, 29, 624.

18 Nitter-Hauge, S, British Heart fournal, 1976, 38, 977.

19 Wilson, W R, in Infections of Prosthetic Valves and Vascular Grafts, ed R J Duma, p 3. Baltimore, University Park Press, 1977.

20 Slaughter, L, Morris, J E, and Starr, A, Circulation, 1973, 47, 1319.

21 Gardner, P, et al, in Infections of Prosthetic Valves and Vascular Grafts, ed R J Duma, p 123. Baltimore, University Park Press, 1977.

22 Anderson, D J, Bulkely, B H, and Hutchins, G M, American Heart Fournal, 1977, 94, 325.

${ }^{23}$ Turnier, E, et al, Chest, 1975, 67, 262.

${ }^{24}$ McLeod, R, and Remington, J S, in Infections of Prosthetic Valves and Vascular Grafts, ed R J Duma, p 163. Baltimore, University Park Press, 1977.

${ }^{25}$ Berkson, J, and Gage, R P, Mayo Clinic Proceedings, 1950, 25, 270.

${ }^{26}$ Anderson, R P, et al, fournal of Surgical Research, 1974, 16, 224.

\section{Sleep apnoea in children}

Even in the fetus regular breathing movements are now regarded as a sign of wellbeing. ${ }^{1}$ After birth, the regular quiet breathing of health is taken so much for granted that it is easy to forget that respiratory pauses may be quite normal, particularly in infancy. Nevertheless, these pauses may sometimes become so frequent and disturbing during sleep that they pose a serious threat to health and even to life.

In older children the sleep apnoea syndrome is associated with snoring, excessive daytime sleepiness, morning headache, poor school performance, and sometimes systemic and pulmonary hypertension. Several hundred spells of apnoea may occur each night so that an affected child may spend more than half the night not breathing. They occur largely in nonREM (rapid eye movement) sleep and invariably lead to partial arousal before the child returns to light sleep. The consequent sleep deprivation may account, at least in part, for the daytime somnolence. When associated with gross obesity this has been labelled the "Pickwickian" syndrome." Similar clinical histories have also been recorded in children with gross tonsillar enlargement in whom cor pulmonale was evident on presentation and they have been successfully cured by adenotonsillectomy. ${ }^{3} 4$

When the cause of the apnoea clearly lies in the upper airway there is no need to invoke any depression of central respiratory function. Guilleminault ${ }^{5}$ has emphasised the overwhelming importance of upper airway factors in sleep apnoea, even in the absence of obesity or overt nasopharyngeal obstruction. Severe snoring, often starting early in life, is always present and suggests an unusual tendency to closure of the upper airways during sleep. In some children a valved tracheostomy has been needed to prevent the cardiovasculan complications that may ensue. ${ }^{6}$

Now that the sudden infant death syndrome (cot death) is thes major cause of postneonatal infant mortality in Britain it is natural that an association should be sought with sleep apnoe Though their frequency falls sharply from birth, the normal 3-month-old infant still has about 80 respiratory pauses eve 100 minutes, most lasting less than 10 seconds. ${ }^{7}$ Nevertheles these occur mostly during active REM sleep and, like the troublesome apnoea of the small pre-term infant, have central origin. A further point of difference is that whereas the older child arouses from his sleep apnoea, the infant may not react at all to prolonged apnoea during sleep. In one study $\overrightarrow{\text { of }}$ 18 normal 6-week-old infants, four showed no response eve्p after 25 seconds' complete nasal obstruction. ${ }^{8}$ Possibly the frequent arrhythmias seen on routine electrocardiographia monitoring of the newborn ${ }^{9}$ may have their counterpart in definite cardiac rhythm abnormalities found in some adults with sleep apnoea. ${ }^{10}$

No single cause seems likely to be found for the sudde infant death syndrome, with its associations. ${ }^{11}$ Nevertheles $\%$, we now know that profound changes of respiratory pattern occur during sleep. These may prove important in somb otherwise inexplicable cases, for only now are we becoming aware of the nature and consequences of these breathin irregularities at all ages from fetal life onwards.

1 Boddy, K, and Dawes, G, British Medical Bulletin, 1975, 31, 3.

2 Burwell, C S, et al, American fournal of Medicine, 1956, 21, 811.

${ }^{3}$ Menashe, V D, Farrehi, C, and Miller, M, Fournal of Pediatrics, 1965 67, 198. 4 Cayler, G G, et al, American fournal of Diseases of Children, 1969, 11 융
708.

5 Guilleminault, C, Tilkian, A, and Dement, W C, Annual Review Medicine, 1976, 27, 465.

6 Guilleminault, C, et al, Pediatrics, 1976, 58, 23.

${ }^{7}$ Gould, J, et al, Pediatrics, 1977, 59, 182.

8 Swift, P G F, and Emery, J L, Archives of Disease in Childhood, 1973, 48 947.

9 Southall, D P, et al, British Medical fournal, 1976, 2, 615

10 Tilkian, A G, et al, Annals of Internal Medicine, 1976, 85, 714

11 Carpenter, R G, et al, Archives of Disease in Childhood, 1977, 52, 606.

\section{Fatal cytomegalovirus infection after renal transplantation}

Many virus diseases have a wide range of features, with subclinical infection at one extreme and severe, sometimes life-threatening illness at the other. This is certainly true of cytomegalovirus (CMV) infection in patients who have had transplant, for laboratory evidence of infection may be found in $60-90 \%$ of them. Some of these infections are reactivation of latent virus and some are primary infections transmitte with the transplanted kidney. According to some groups, the reactivations tend largely not to be associated with symptoms; whereas primary infections are clinically obvious. ${ }^{34}$ Never theless, in other studies ${ }^{15}$ clinical disease has been associate with both reactivations and primary infections. The commor features include fever, arthralgia, pneumonitis, hepatitis, and deterioration in renal function with histological evidence of rejection of the transplanted kidney. There is a definite rise in antibody titre to CMV. Though some of these features may 
persist for weeks in an individual patient, typically the disease is self-limiting.

A fatal form of CMV infection has now been described ${ }^{56}$ as a result of a prospective study of virus infections in renal transplant recipients. This variant was identified in eight of 377 patients who had received 441 transplants over six years. The illness started with a spiking fever and in the first week there was hypotension; hypoxaemia (with no other clinical or radiological signs of a lung disorder); thrombocytopenia; lymphopenia; and deterioration in renal function. In the second week the patient became lethargic, weak, and bedridden, with peripheral oedema, muscle wasting, and hypoxaemia. All these features became more severe during the next two weeks, liver and kidney function deteriorating further and diffuse interstitial pneumonia developing. The eight patients described all died during the fourth week with acidosis, irreversible hypotension, and pulmonary oedema. At necropsy all had pneumonitis and multiple scattered ulcerations of the gastrointestinal tract, but the grafted kidneys showed no evidence of acute rejection, and chronic rejection was present in only three of the eight patients.

No evidence of infection could be obtained during the first week, and the only evidence in the second week was the occurrence of CMV inclusion bodies in cells obtained in bronchial washings. Nevertheless, in the third and fourth weeks cytomegalovirus was cultured from urine, sputum, bone marrow, or renal biopsy specimens in six of the eight cases. At necropsy $\mathrm{CMV}$ inclusions were seen and virus was isolated from lung, brain, liver, kidney, and the gastrointestinal tract. Intestinal bacteria and fungi (especially aspergillus and candida) were also isolated from the lungs, gastrointestinal tract, heart, and blood. CMV antibody could not be detected in any of the patients throughout the illness-except that in one patient a titre of 1/64 was found on the day before death.

Pneumonitis associated with CMV has been described repeatedly in immunocompromised patients. In a period of four years at Stanford CMV was isolated from the lungs of nine recipients of organ transplants and seven patients with tumours. ${ }^{7}$ All had fever, non-productive cough, and dyspnoea. Twelve (of whom 11 died) had hypoxaemia, whereas all those without hypoxaemia survived. Only seven showed a CMV antibody response. In another series, of 150 patients given bone marrow transplants, over half developed interstitial pneumonitis within the first four months and in half the patients the pneumonia was a fulminant lethal illness. ${ }^{8-10}$ CMV was recovered from lung tissue in over half those with pneumonitis, but a definite rise in the CMV antibody titre was found in only about a third of them. The prognosis was much worse if there was no antibody response: indeed, in one series $^{10}$ all 13 such patients with CMV pneumonitis died.

CMV pneumonitis in recipients of organ transplants may, then, be a transient condition with recovery associated with a specific antibody response. Alternatively, severe pneumonitis may occur with death from respiratory failure in the absence of an antibody response. The fatal form seems to develop in about $2 \%$ of recipients of renal transplants but it may be ten times more frequent in recipients of marrow transplants. Other organisms (Pneumocystis carinii, fungi, intestinal bacteria) may be isolated from the lungs of some of these patients, but in some at least CMV is the only pathogen isolated. Definite antemortem diagnosis depends on finding $\mathrm{CMV}$ in lung aspirate or biopsy material. Culture of the virus may take weeks, but rapid diagnosis may be possible by staining for CMV antigen by immunofluorescence.

No specific prevention or treatment is available at present.
Nevertheless, since the fatal form appears to be related to a lack of an immune response by the host, the doctor must consider decreasing the immunosuppression in any patient with a typical clinical illness in whom a renal biopsy specimen shows no evidence of rejection.

\footnotetext{
1 Fiala, M, et al, fournal of Infectious Diseases, 1975, 132, 421.

2 Balfour, H H, et al, Surgery, 1977, 81, 487.

3 Betts, R F, et al, American fournal of Diseases of Children, 1977, 131, 759

4 Betts, R F, and Hanshaw, J B, Annual Review of Medicine, 1977, 28, 103.

5 Simmons, R L, et al, Annals of Surgery, 1974, 180, 623.

6 Simmons, R L, et al, Surgery, 1977, 82, 537.

7 Abdullah, P S, Mark, J B D, and Merigan, T C, American fournal of Medicine, 1976, 61, 326

${ }^{8}$ Meyers, J D, et al, Annals of Internal Medicine, 1975, 82, 181.

9 Pagano, J S, Fournal of Infectious Diseases, 1975, 132, 114.

10 Neiman, P E, et al, fournal of Infectious Diseases, 1977, 136, 754.
}

\section{Utility of needle aspiration of tumours}

The surgical world is divided into two classes: those who believe it is wrong to assault a tumour by anything less than its formal excision and those who are prepared to pass needles of varying size into it to reach either a cytopathological ${ }^{1}$ or a histopathological ${ }^{2}$ diagnosis ahead of definitive treatment. There is no satisfactory evidence in man on whether needle aspiration is dangerous or safe, so that the choice between the conservative and interventionist schools is an article of faith. Nevertheless, it is incumbent on the interventionist to prove utility before the practice is widely adopted.

Utility is built on three foundations: practical success, sensitivity, and discrimination. Success with needle aspiration means the production of a satisfactory specimen by the clinician and the preparation of a reportable smear by the cytopathologist. Though results in different centres and for different organs vary, the going rate for unreportable specimens should be certainly less than $10 \%$ and probably less than 5\%. ${ }^{3-5}$ Most of the failures will result from the needle's missing the lesion, but sometimes the target may be so acellular that a good sample is impossible. Success rates may be artificially inflated if specimens such as cyst fluid are included. ${ }^{4}$ Sensitivity means the ability to detect malignancy when it is present. Again, rates vary. In the breast $90 \%$ sensitivity has been reached and in other tissues (for example, the lung) it may be higher. ${ }^{6}$ Discrimination depends on the results of the procedure of sorting clinically doubtful lesions into benign and malignant. Here achievement is less impressive $-50-60 \%$ only are correctly assigned..$^{4}$

But utility must be judged on more than correct assignment to diagnostic classes: the final arbiter is how a technique influences clinical practice for good or ill. With cytological tests the question cannot be answered directly, since those interested have not expressed their results in such terms, accepting instead the premise that if something works it is thereby useful. When challenged, most of those who seek cytological specimens would agree that a histopathological diagnosis is necessary before ablative surgery or other radical treatment, such as chemotherapy or radiotherapy. If that is the case, what is the use of needle aspiration cytology? Where does it fit in the diagnostic sequence? The answer remains uncertain but should probably not be sought in the black-and-white terms of the dichotomy between benign and malignant. Different frames of reference should be used: firstly, how may 